\title{
Water Relations of a Fragaria chiloensis and a $F$. virginiana Selection during and After Water Deficit Stress
}

\author{
Baolin Zhang ${ }^{1}$ and Douglas D. Archbold ${ }^{2}$ \\ Department of Horticulture and Landscape Architecture, University of Kentucky, Lexington, KY 40546
}

Additional index words. strawberry, drought resistance, osmotic adjustment

\begin{abstract}
A comparative study was performed to elucidate changes in the water relations of Fragaria chiloensis (L.) Duch. 'BSP14' (FC) and F. virginiana (L.) Duch. 'NCC85-13V' (FV), grown in containers in a greenhouse, in response to imposed water deficit stress and subsequent recovery. At incipient wilting, a reduction in osmotic potential at full turgor ( $\Psi_{\pi}{ }^{100}$ ) of $0.42 \mathrm{MPa}$ occurred in leaves of FC, while no change was found in FV. Leaf water potential ( $\Psi$ ) isotherms revealed that as leaf $\Psi$ and relative water content $(\mathrm{RWC})$ declined, stressed $F C$ plants maintained a higher turgor potential ( $\Psi_{\mathrm{p}}$ ) and lower osmotic potential $\left(\Psi^{\pi}\right)$ than nonstressed (control) plants, while there was no effect of drought stress on these relationships in the FV plants. From the isotherms, turgor loss was estimated to occur at a lower leaf $\Psi$ and RWC in stressed FC plants than either in control FC plants or stressed and control FV plants. During a diurnal phase 36 hours after wilting, leaf $\Psi$, $\Psi_{n}$, and RWC of the FC selection were generally lower in stressed than in control plants, with differences ranging from 0.14 to $0.74 \mathrm{MPa}, 0.28$ to $0.47 \mathrm{MPa}$, and $1 \%$ to $8 \%$, respectively. In the FV selection, $\Psi_{\pi}$, was 0.09 to $0.31 \mathrm{MPa}$ lower in stressed than in control leaves, while the other characteristics were not affected. Leaf $\Psi_{\mathrm{p}}$, of stressed FC plants was 0.09 to $0.27 \mathrm{MPa}$ higher than controls during the dark period, but was similar during the day. When plants of both species were grown and stressed in the same container, FV plants wilted $\approx 4$ days earlier than FC plants, and foliar $\Psi_{\pi}{ }^{100}$ of $\mathrm{FC}$ was $0.35 \mathrm{MPa}$ lower than that of FV at incipient wilting. The isothermal relationships between leaf $\Psi$ and $\Psi_{\pi}{ }^{100}$ indicated ${ }^{\pi}$ C had a $\Psi_{\pi}{ }^{100} \approx 0.25$ MPa lower than FV at a $\Psi<1.5$ MPa. This study provided evidence for greater osmotic adjustment in response to imposed water deficit stress in a selection of $F$. chiloensis than in one of $F$. virginiana.
\end{abstract}

Water availability has a significant impact on strawberry plant growth and yield (Dwyer et al., 1987; Gehrmann, 1985; Renquist et al., 1982a, 1982b). In the genus Fragaria, there may be great variation in drought resistance among cultivars and wild species (Archbold and Zhang, 1991; Chandler and Ferree, 1990; Darrow and Dewey, 1934; Mazhorov, 1978). Commercial strawberry cultivars ( $F$. Xananassa Duch.) are direct or indirect hybrids of the putatively drought-resistant $F$. chiloensis Duch. and the droughtsusceptible $F$. virginiana Duch. The mechanism(s) for drought resistance in Fragaria is not clear.

The reduction of leaf turgor potential $\left(\Psi_{\mathrm{p}}\right)$ that accompanies the loss of water from leaf tissue directly affects many important morphological and physiological processes, such as leaf enlargement, stomatal aperture, photosynthesis, and $\mathrm{N}$ assimilation (Hsiao, 1973; Hsiao et al., 1976; Kramer, 1983; Turner and Jones, 1980). As leaf water potential declines, strawberry photosynthetic rate declines, indicating sensitivity to drought stress (Sruamsiri and Lenz, 1986). Many plant species adjust to water deficits and maintain leaf $\Psi_{\mathrm{p}}$ as leaf water potential $(\Psi)$ declines. The relationship between leaf $\Psi$ and $\Psi_{\Pi}$, may be altered by drought stress preconditioning so that previously stressed plants may have a lower leaf $\Psi$ at zero turgor than nonstressed ones (Jones and Turner, 1978; Turner, 1986; Turner and Jones, 1980). This situation leads to a reduction in the critical leaf $\Psi$ or relative water content (RWC) at which physiological and morphological processes are

Received for publication 20 Mar. 1992. Accepted for publication 1 Sept. 1992. The investigation reported in this paper (92-10-44) is in connection with a project of the Kentucky Agricultural Experiment Station and is published with the approval of the director. The cost of publishing this paper was defrayed in part by the payment of page charges. Under postal regulations, this paper therefore must be hereby marked advertisement solely to indicate this fact.

'Graduate Research Assistant. Current position and address: Postdoctoral Research Asssociate, Dept. of Forestry, Univ. of Kentucky, Lexington, KY 40546.

${ }^{2}$ Associate Professor. To whom reprint requests should be addressed. affected (Farquhar and Sharkey, 1982; Turner, 1986; Turner and Jones, 1980).

Osmotic adjustment, the active accumulation of leaf solutes lowering leaf osmotic potential $\left(\Psi_{\pi}\right)$, is a process by which many species respond and adjust to drought and/or salinity (Barlow, 1986; Hsiao, 1973; Morgan, 1984; Turner, 1986; Turner and Jones, 1980). Osmotic adjustment allows the aforementioned turgor-regulated processes to continue at progressively lower leaf $\Psi$ and maintains water extraction from the soil as the root $\Psi$ decreases (Ludlow and Muchow, 1990; Turner, 1986). Following adjustment, the leaf can maintain photosynthesis at lower leaf $\Psi$ (Jones and Rawson, 1979); thus, the supply of assimilates to actively growing sites can continue.

Renquist et al. (1982c) reported that osmotic adjustment was exhibited in 'Olympus' strawberry. Diurnal leaf $\Psi_{\mathrm{p}}$, was maintained, while $\Psi$ and $\Psi_{\pi}$, declined in nonirrigated plants in the field. They concluded that the maintenance of leaf $\Psi_{\mathrm{p}}$ in nonirrigated plants, despite lower $\Psi$, was due to diurnal osmotic adjustment in the leaves. However, the maintenance of leaf $\Psi_{\mathrm{p}}$ could also be due to increasedelasticity of the leaf cell walls (Elston et al., 1976; Kim and Lee-Stadelmann, 1984; Turner and Jones, 1980). Osmotic adjustment cannot be confirmed unless the reduction of $\Psi_{\pi}$, due to the accumulation of osmotically active solutes is verified. By using the pressure-volume technique and establishing the foliar water content to $\Psi_{\pi}$, relationships for well-watered and water-stressed plants, O'Neill(1983) concluded that osmotic adjustment occurred in water-stressed plants of a F. virginiana selection. Fragaria chiloensis is reportedly much more drought-resistant than F. virginiana; however, little information is available on the comparative drought stress physiology of either species under similar water deficit

Abbreviations: FC, Fragaria chiloensis (L.) Duch. 'BSP14'; FV, Fragaria virginiana (L.) Duch. 'NCC85-13V'; RWC, relative water content; $\Psi$, water potential; $\Psi_{\mathrm{p}}$, turgor potential; $\Psi_{n}$, osmotic potential; $\Psi \pi^{100}$, osmotic potential at full turgor. 
induction conditions. Morphological adaptations, hypothesized as the source of drought response variation (Darrow, 1966), are not solely responsible for the differences in drought resistance between selections of these and other Frugaria species (Archbold and Zhang, 1991).

Increasing drought stress resistance in cultivated varieties may be possible via breeding and biotechnological methods, but only when those traits conferring resistance have been determined. Preliminary observations indicated that a $F$. chiloensis selection, 'BSP14', had greater drought resistance than a $F$. virginiana selection, 'NCC85-13V' (Archbold and Zhang, 1991), fitting the reported drought-resistance classification of each species (Darrow, 1966). The objectives of this study were to characterize the water relations of the drought-resistant $F$. chiloensis selection and the drought-susceptible $F$. virginiana selection during and after imposed water deficit stress to determine if osmotic adjustment occurs in either species.

\section{Materials and Method}

Plant materials and stress imposition. Plants of $F$. chiloensis 'BSP14' (FC) were obtained from the National Germplasm Repository in Corvallis, Ore. Plants of $F$. virginiana 'NCC85-13V' (FV) were obtained from Ronald Goldy, North Carolina State Univ., Raleigh. Plants were propagated by runner cuttings and were 4 months old when the experiments were started. They were maintained in containers $(2.41,15 \mathrm{~cm}$ diameter) containing ProMix BX (Premier Brands, Stamford, Conn.), unless indicated otherwise. All plants were watered daily and received a $200 \mathrm{ppm}$ $20 \mathrm{~N}-20 \mathrm{P}-20 \mathrm{~K}$ fertilizer solution weekly until the experiments started. The greenhouse was at $21 \pm 6 \mathrm{C}$ with ambient light levels during the experiments. To induce water deficit stress, water was withheld from plants until at least $50 \%$ of the plants of a selection exhibited incipient wilting at midday, or loss of leaf petiole turgor. All plants were then re-watered daily during the recovery period. Control plants were watered daily.

Leaf sampling and measurement of water relation components. Leaf $\Psi$ was measured on the most recent fully expanded, mature leaf of each test plant using a pressure chamber (Model 610, PMS Instruments, Corvallis). Leaves were sampled between 1000 and $1200 \mathrm{HR}$ unless otherwise indicated. The procedure was basically the same as that described by Turner (1988). Briefly, the leaf was cut at the petiole base and immediately placed in the pressure chamber with $\approx 0.5 \mathrm{~cm}$ of the cut end of the petiole protruding through the rubber stopper used to seal the chamber. The pressure in the chamber was gradually increased by applying compressed $\mathrm{N}_{2}$ gas until the sap returned to the cut end of the main xylem vessels, monitored with a magnifying lens. The pressure inside the chamber was recorded and released before the leaf was removed. Once removed from the pressure chamber, the leaf was immediately sealed in a plastic bag, placed in a Dewar flask containing icecold tap water to minimize water loss from the leaves, and transported to the laboratory. In the laboratory, the three leaflets of each sampled leaf were used for measurements of $\Psi_{\pi}, \Psi_{\pi}{ }^{100}$, and RWC, respectively. For measurement of $\Psi_{\pi}$, one leaflet from each sampled leaf per test plant was placed in an aluminum sample cup, sealed with Parafilm, and frozen at -20C. It was thawed for $2 \mathrm{~h}$ inside the sealed cup at room temperature, and the cup was then placed in a Decagon SC- 10 thermocouple psychrometer connected to a NT-3 nanovoltmeter (Decagon Devices, Pullman, Wash.). Voltage readings were taken after a minimum 2-h temperature equilibration. Voltage $(\mu \mathrm{V})$ was converted to MPa by the use of a regression of voltage against a series of $\mathrm{KC} 1$ standards of known
$\Psi_{\pi}$. The leaf $\Psi_{\mathrm{p}}$, was calculated as the difference between $\Psi$ and $\Psi_{\pi}$, or $\Psi_{\mathrm{p}}=\Psi-\Psi_{\pi}$.

The two remaining leaflets from each sampled leaf, one of which had been weighed, were floated on distilled deionized water for $12 \mathrm{~h}$ in a covered petri dish at ambient laboratory temperature. They were then blotted dry and one was used for the measurement of $\Psi_{\pi}{ }^{100}$ in the same way as for $\Psi_{\pi}$. For determination of RWC, the remaining leaflet was reweighed to get turgid weight (TW), then oven-dried for $16 \mathrm{~h}$ at $80 \mathrm{C}$. RWC was calculated as follows: RWC $=((\mathrm{FW}-\mathrm{DW}) \div(\mathrm{TW}-\mathrm{DW})) \times 100$, where $\mathrm{FW}$ was initial fresh weight and DW was the oven-dry weight (Turner, 1988).

Rapid stress induction and recovery. Four single-plant replicates of each species and treatment at each sampling date were used. Starting on day 0, the final watering date, the most recent fully mature leaf of each plant was sampled on each of four dates until incipient wilting. Sampling intervals of 2 days started on day 3 for FC plants and were daily starting on day 2 for FV plants. Stressed plants were watered for a recovery period equal to half the length of the wilting cycle for each species, then sampled. The experiment was conducted in May 1989.

Characterization of leaf $\Psi$ isotherms. From both control and stressed plants of each species, following an experiment as described above, a recently matured leaf was sampled from 14 to 18 individual plants at incipient wilting. Intact leaves were floated on distilled deionized water to achieve full turgor as for the measurement of RWC. After being blotted dry, the leaves were placed on a laboratory bench to undergo desiccation at ambient temperature $(23 \pm 2 \mathrm{C})$ and light intensity $\left(10 \mu \mathrm{mol} \cdot \mathrm{m}^{-2} \cdot \mathrm{s}^{-1}\right)$. During desiccation, $\Psi, \Psi_{\pi}$, and RWC were determined on randomly selected leaves as described previously. From these data, plots of $\Psi, \Psi_{\pi}$, and $\Psi_{\mathrm{P}}$ against RWC as well as plots of $\Psi_{\mathrm{p}}$ and $\Psi_{\pi}$, against $\Psi$ were made as described by Jones and Turner (1978).

Poststress diurnalphase. Plants of each selection were stressed once as described above. One recently matured leaf was removed from each of four single-plant replicates for each selection and treatment at each sampling time. Thirty-six hours after re-watering, starting at $0000 \mathrm{HR}$, light intensity, $\Psi, \Psi$, and RWC were measured at 2-h intervals. The experiment was conducted in May 1989.

Slow stress induction. Two runner plants of each selection were rooted opposite one another in the same container $(151,27 \mathrm{~cm}$ diameter) containing washed sand (U.S. Sand, Ottawa, Ill.). There were six replicate pots at each sampling date. After 50 days, starting 15 Sept. 1989, water was withheld from the plants. The date of incipient wilting was recorded for each plant. Starting at day 73, 23 days after withholding water, one fully mature leaf per plant was sampled at $1000 \mathrm{HR}$ at 4- to B-day intervals to measure leaf $\Psi$ and $\Psi_{\tau}^{100}$. Leaves were sampled from each plant until the final plant in each pot reached wilting. The mean value of leaf $\Psi$ and $\Psi_{\pi}{ }^{100}$ from the pair of plants of each species in each pot was recorded as the response.

All treatments within each experiment were randomly arranged on a greenhouse bench under ambient conditions. Significant differences between control and stress plant means were determined by $t$ test. Linear or quadratic functions were fitted to isotherm data if the relationship was significant $(P>0.05)$.

\section{Results}

Rapid stress induction and recovery. At least $50 \%$ of stressed FV plants exhibited incipient wilting 3 days after withholding of water, while those of FC wilted on day 9. For FC, leaf $\Psi$ of stressed plants did not differ from control plants during the first 4 days after watering ceased (Fig. 1A). By day 7 , leaf 4 was $0.29 \mathrm{MPa}$ below 


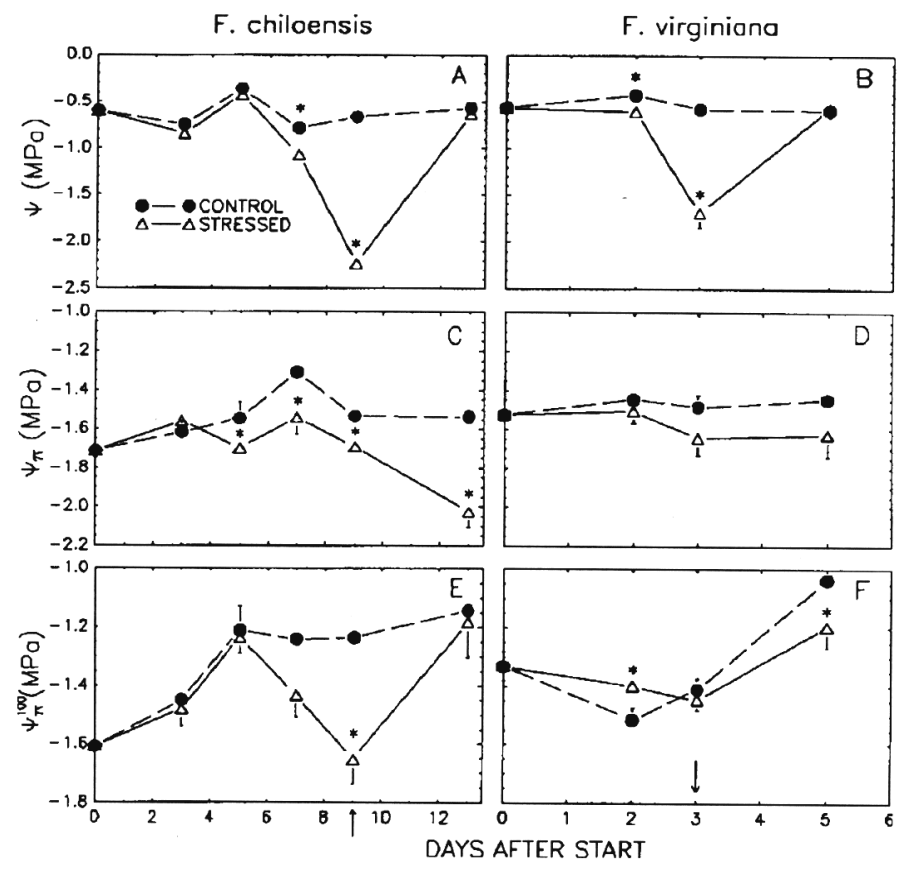

Fig. 1. Leaf $\Psi(\mathbf{A}, \mathbf{B}), \Psi_{\pi}(\mathbf{C}, \mathbf{D})$, and $\Psi_{\pi}^{100}(\mathrm{E}, \mathrm{F})$ of control and stressed $F$. chiloensis $(\mathbf{A}, \mathbf{C}, \mathbf{E})$ and F. virginiana $(\mathbf{B}, \mathbf{D}, \mathbf{F})$ plants during and after drought stress. Plants were re-watered starting the day indicated by the arrow. Each data point represents the mean of four measurements. Bars indicate the SE of the mean and are not shown if they are smaller than the symbols. An asterisk (*) indicates a significant difference between control and stressed plant means by $t$ test at $P \leq$ 0.05 .

controls and decreased to $-2.23 \mathrm{MPa}, 1.56 \mathrm{MPa}$ below controls, when plants started to wilt. The leaf $\Psi$ of the FV selection declined to -1.69 MPa, 1.1 MPa below controls, on day 3 when stressed plants started to wilt (Fig. 1B). Leaf $\Psi$ returned to control levels during recovery for both species. In FC, leaf $\Psi_{\pi}$ of stressed plants was consistently below controls after 3 days of stress and through recovery (Fig. 1C). In FV, the $\Psi_{\pi}$ of stressed plants did not differ from control plants at incipient wilting and through recovery (Fig. 1D). In FC, leaf $\Psi_{\pi}^{100}$ was $0.19 \mathrm{MPa}$ below the control value before wilting (Fig. 1E). The $\Psi_{\pi}{ }^{10}{ }^{0}{ }^{0}$ at incipient wilting was $0.42 \mathrm{MPa}$ lower than controls. After recovery, leaf $\Psi_{\pi} 100$ returned to control levels. For stressed FV plants, however, leaf $\Psi_{\pi}^{100}$ was higher than controls 1 day before wilting, but was $0.2 \mathrm{MPa}$ lower than controls after the recovery period (Fig. $1 \mathrm{~F}$ ).

Leaf $\Psi$ isotherms. The relationships of leaf $\Psi_{\pi}$ and $\Psi_{\mathrm{p}}$, with RWC for the FC selection were altered by a prior drought stress, while leaf $\Psi$ was not (Fig. 2 A, C, and E). As leaf water content declined, leaf $\Psi_{\mathrm{P}}$ was higher and leaf $\Psi_{\pi}$, was lower in the stressed than in control plants. For example, at 30\% water loss, or a RWC of $70 \%$, estimates of leaf $\Psi, \Psi_{\pi}$, and $\Psi_{\mathrm{P}}$ were $-2.19,-1.63$, and $-0.52 \mathrm{MPa}$, respectively, for control plants, whereas they were $-1.76,-2.55$, and $0.16 \mathrm{MPa}$, respectively, for stressed plants of FC. At a $\Psi_{\mathrm{P}} \mathrm{o}$ f zero, RWC was $84 \%$ and $60 \%$ for control and stressed plants, respectively. The relationships of leaf $\Psi, \Psi_{\pi}$, and $\Psi_{\mathrm{P}}$ with RWC for FV were not altered appreciably by stress (Fig. 2 B, D, and F). Stressed FV plants wilted at a leaf $\Psi$ of $-1.65 \mathrm{MPa}$ and a RWC of $82 \%$.

The relationships of leaf $\Psi_{\pi}$ and $\Psi_{\mathrm{p}}$ with $\Psi$ in FC were also altered by prior stress (Fig. $3 \mathrm{~A}$ and $\mathrm{C}$ ). Leaf $\Psi_{\mathrm{p}}$ reached zero when the leaf $\Psi$ was -1.4 and $-2.8 \mathrm{MPa}$ for control and stressed plants, respectively. These relationships were not appreciably altered in the FV selection (Fig. $3 \mathrm{~B}$ and D).

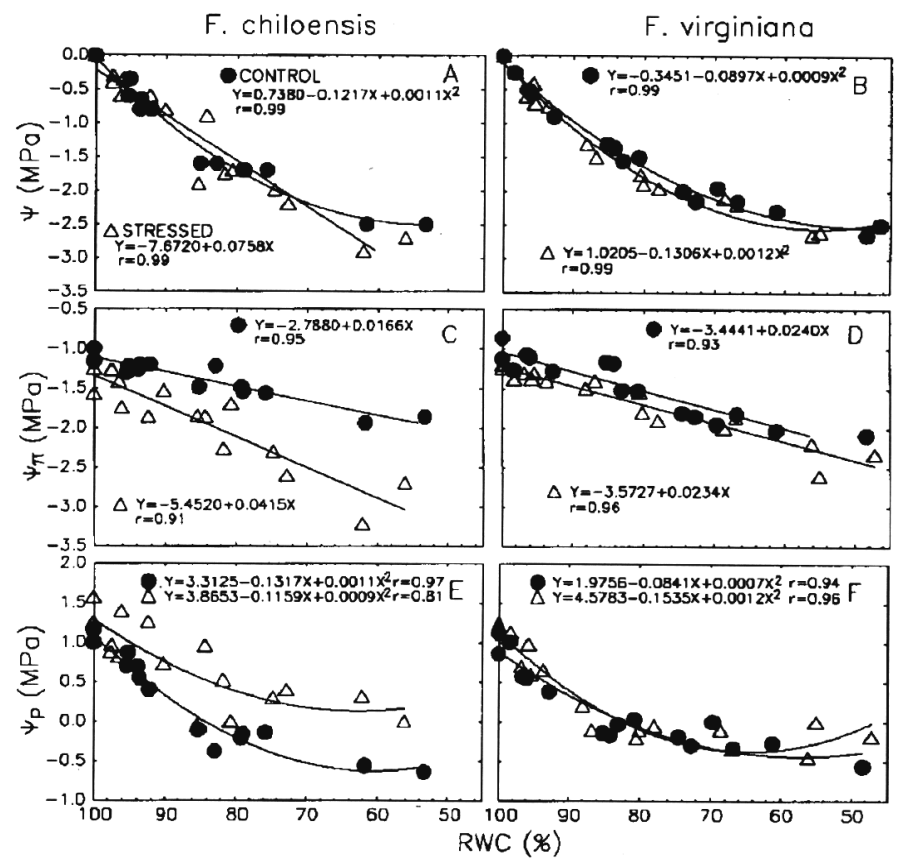

Fig. 2. Relationships of leaf $\Psi(\mathbf{A}, \mathbf{B}), \Psi_{\tau}(\mathbf{C}, \mathbf{D})$, and $\Psi_{\mathrm{p}}(\mathbf{E}, \mathbf{F})$ with leaf RWC for control and stressed $F$. chiloensis $(\mathbf{A}, \mathbf{C}, \mathbf{E})$ and $F$. virginiana $(\mathbf{B}, \mathbf{D}, \mathbf{F})$ plants after drought stress. Measurements were made on 14 to 18 leaflets from separate plants during desiccation after the leaflets were rehydrated to full turgor. Each data point represents one measurement or a single leaf.

Poststress diurnal phase. The leaf $\Psi$ of stressed FC plants was generally lower than controls over the diurnal period (Fig. 4A). During the dark period, leaf $\Psi$ of stressed FC plants averaged -0.4 $\mathrm{MPa}, \approx 0.2 \mathrm{MPa}$ below that of controls. By $1000 \mathrm{HR}$ it had dropped sharply, to a low of $-1.37 \mathrm{MPa}, 0.74 \mathrm{MPa}$ below that of the controls, which had also declined from predawn values. Leaf $\Psi$ remained below -1.0 $\mathrm{MPa}$ through $1600 \mathrm{HR}$ until increasing to -0.7 MPa by $1800 \mathrm{HR}$. For FV, leaf $\Psi$ showed similar diurnal variation, but values for stressed plants were lower than those of control plants at 1200 HR only (Fig. 4B).

Leaf $\Psi_{\pi}$, of stressed plants of both species was consistently lower
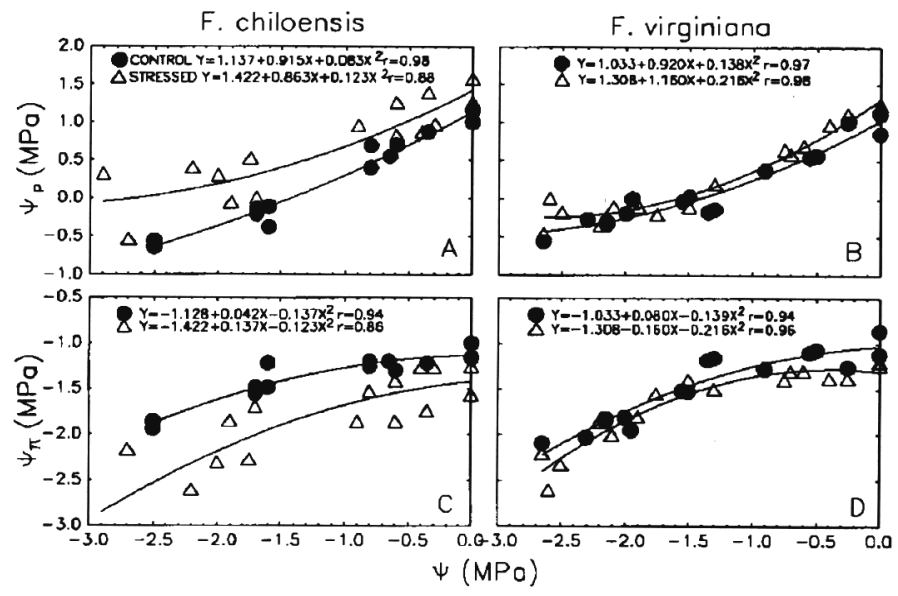

Fig. 3. Relationships of leaf $\Psi_{\mathrm{p}}(\mathbf{A}, \mathbf{B})$ and $\Psi_{\pi}(\mathbf{C}, \mathbf{D})$ with leaf $\Psi$ for $F$. chiloensis $(\mathbf{A}, \mathbf{C})$ and $F$. virginiana $(\mathbf{B , D})$ plants following drought stress. Measurements were made on 14 to 18 leaflets from separate plants during desiccation after the leaflets were rehydrated to full turgor. Each data point represents one measurement or a single leaf at a RWC. 


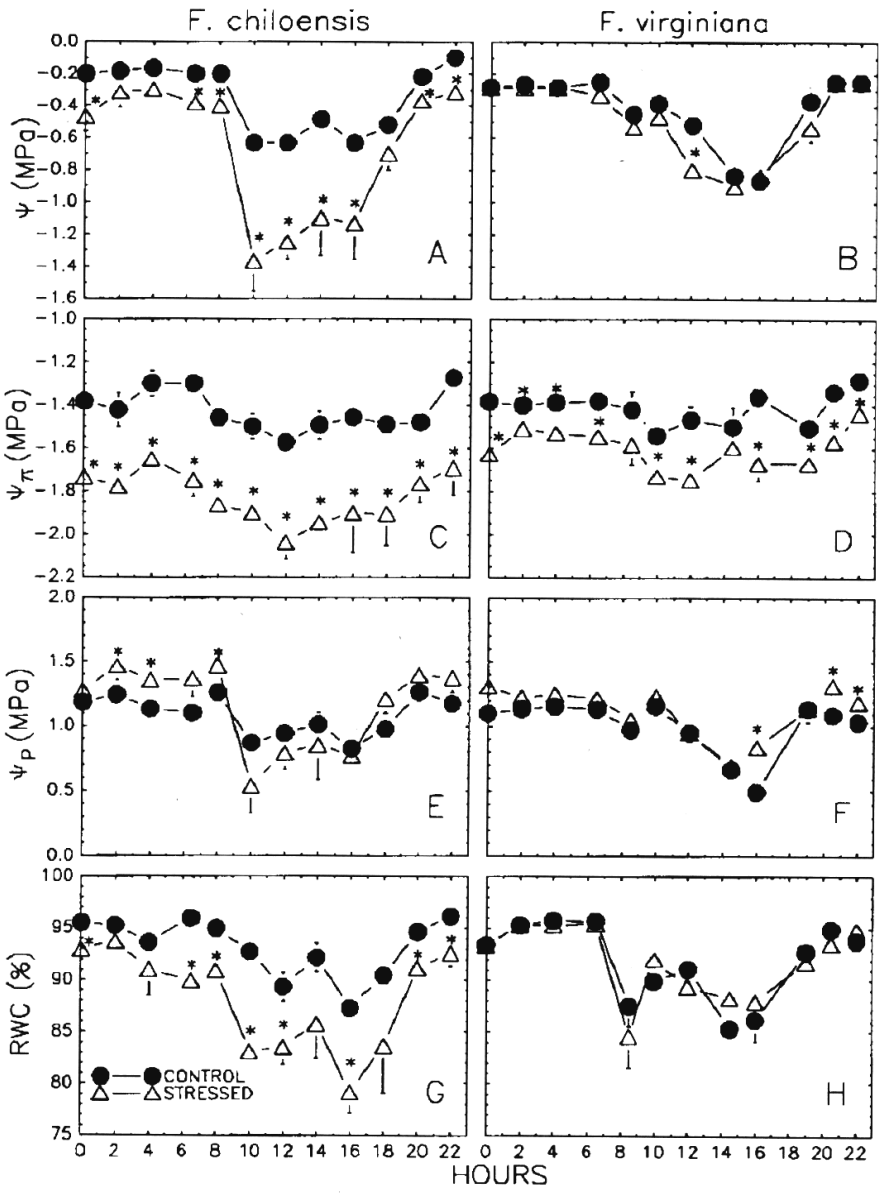

Fig. 4. Diurnal changes in leaf $\Psi(\mathbf{A}, \mathbf{B}), \Psi_{\pi}(\mathbf{C}, \mathbf{D}), \Psi_{\mathrm{p}}(\mathbf{E}, \mathbf{F})$, and RWC $(\mathbf{G}, \mathbf{H})$ of control and previously stressed $F$. chiloensis $(\mathbf{A}, \mathbf{C}, \mathbf{E}, \mathbf{G})$ and $F$. virginiana $(\mathbf{B}$, D,F,H) plants. Measurements were made $36 \mathrm{~h}$ after the stressed plants were rewatered. Each data point represents the mean of four single plant replicates. Bars indicate the SE of the mean and are not shown if they are smaller than the symbols. An asterisk $(*)$ indicates a significant difference between control and stressed plant means by $t$ test at $P \leq 0.05$.

than that of controls, but the magnitude of the difference was consistently greater for FC than for FV (Fig. $4 \mathrm{C}$ and D). The mean leaf $\psi_{\pi}$ of stressed FC plants was $0.4 \mathrm{MPa}$ below the control mean, with a maximum difference of $0.47 \mathrm{MPa}$ at $1200 \mathrm{HR}$ and a minimum difference of $0.28 \mathrm{MPa}$ at $2000 \mathrm{HR}$. For FV, the mean difference in leaf $\psi_{\pi}$ between the control and stressed plants was $0.19 \mathrm{MPa}$ with a maximum difference of $0.31 \mathrm{MPa}$ at $1600 \mathrm{HR}$ and a minimum difference of $0.09 \mathrm{MPa}$ at $1400 \mathrm{HR}$. The mean predawn leaf $\psi_{\pi}$ of stressed plants, between 0000 and $0630 \mathrm{HR}$, was 0.38 and $0.17 \mathrm{MPa}$ lower than that of control plants for the FC and FV selections, respectively.

The pattern of diurnal change in leaf $\psi_{\mathrm{p}}$ of control and stressed plants of both species was similar to that for leaf $\psi$ (Fig. $4 \mathrm{E}$ and F). For the FC selection, the mean predawn leaf $\psi_{\mathrm{p}}$ of stressed plants, between 0000 and $0630 \mathrm{HR}$, was $0.21 \mathrm{MPa}$ higher than that of controls. From 0800 through $1600 \mathrm{HR}$, the leaf $\psi \mathrm{P}$ of stressed plants fell below that of controls, ranging from 0.54 to $0.85 \mathrm{MPa}$ for stressed plants, and from 0.82 to $1.01 \mathrm{MPa}$ for controls. The lowest value, $0.54 \mathrm{MPa}$, occurred at $1000 \mathrm{HR}$, when leaf $\psi$ was at its lowest. For FV, the mean predawn leaf $\psi_{\mathrm{p}}$ of stressed plants was $0.15 \mathrm{MPa}$ higher than that of controls. The minimum leaf $\psi_{\mathrm{P}}$ was $0.67 \mathrm{MPa}$ for stressed and 0.49 MPa for control plants, occurring at 1400 and $1600 \mathrm{HR}$, respectively.
There was diurnal variation in leaf RWC of both species (Fig. $4 \mathrm{G}$ and $\mathrm{H}$ ). During the dark period, leaf RWC was $>90 \%$ for control and stressed plants of both species. During the day, leaf RWC reached its lowest levels. The leaf RWC of the stressed FC plants averaged 5\% lower than that of control plants throughout the 24-h period. For FV, the diurnal fluctuation of leaf RWC was similar to that of FC, but there was no difference between control and stressed plants, nor were the leaf RWC's of stressed FV plants as low as those for the FC selection.

Slow stress induction. When grown and stressed in the same pot, the mean time to incipient wilting was $31 \pm 2$ and $35 \pm 2$ days for the FV and FC selections, respectively. No difference in the rate of leaf $\psi$ decline was observed between the selections (Fig. 5A). Foliar $\psi_{\pi}^{100}$ was similar until 37 days after withholding water, when it was $\approx 0.35 \mathrm{MPa}$ lower in FC than FV (Fig. 5B). The isothermal relationship between leaf $\psi_{\pi}^{100}$ and $\psi$ showed that the $\psi_{\pi}{ }^{100}$ of $\mathrm{FC}$ was $\approx 0.25 \mathrm{MPa}$ lower than that of $\mathrm{FV}$, when leaf $\psi$ was lower than -1.5 MPa (Fig. 6).

\section{Discussion}

The diurnal phase measurements showed that between 1000 and $1200 \mathrm{HR}$, leaf $\psi_{\pi}$ was lower for stressed than for control plants of both species (Fig. 4). Differences between control and stressed plants at midday were greater than predawn differences, in contrast to results of a study of the Fragaria ×ananassa Duch. cultivar Olympus (Renquist et al., 1982c). Leaf $\psi_{\pi}$ at midday likely reflected both diurnal and stress-induced osmotic adjustment (Jones

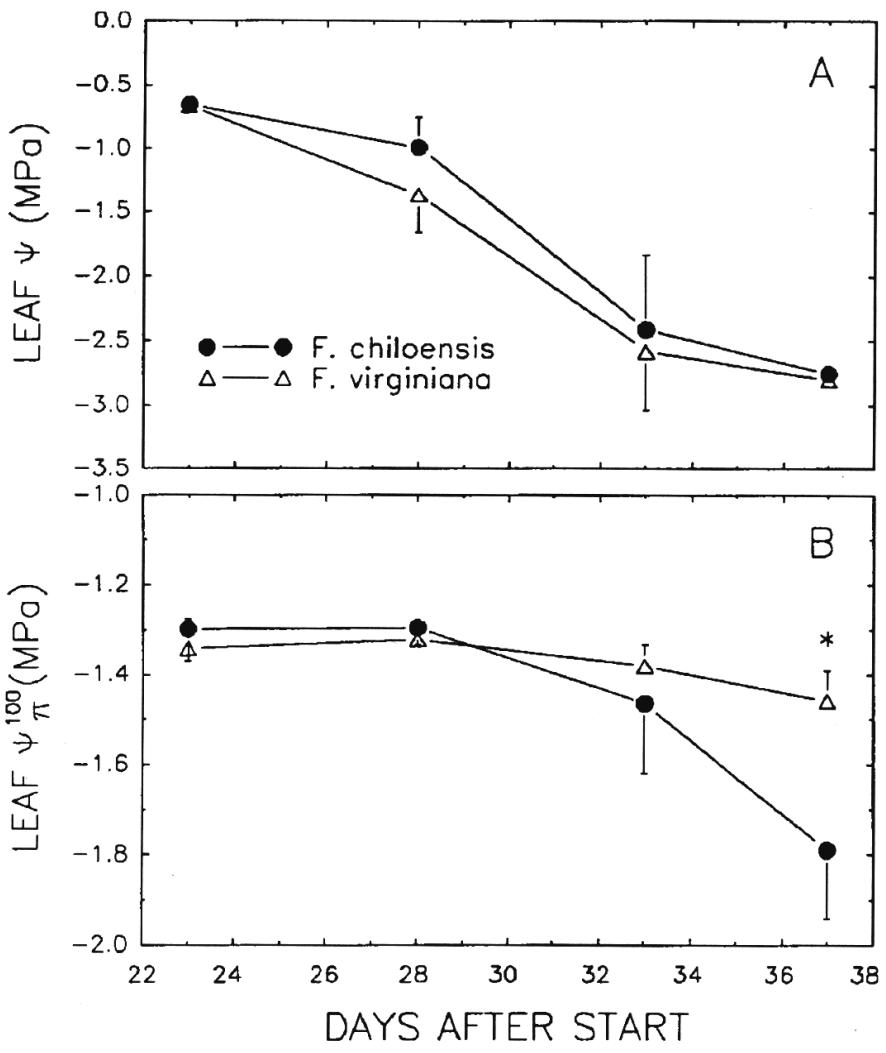

Fig. 5. Leaf $\psi(\mathbf{A})$ and leaf $\psi_{x}^{100}(\mathbf{B})$ of $F$. chiloensis and $F$. virginiana under slowly induced water deficit stress. Two plants each of both species were grown in the same pot. Water was withheld from the plants 50 days after rooting, and measurements of leaf $\psi$ and $\psi_{\pi}^{100}$ started 23 days after withholding water. Each data point is the mean of six single plant replicates SE. 


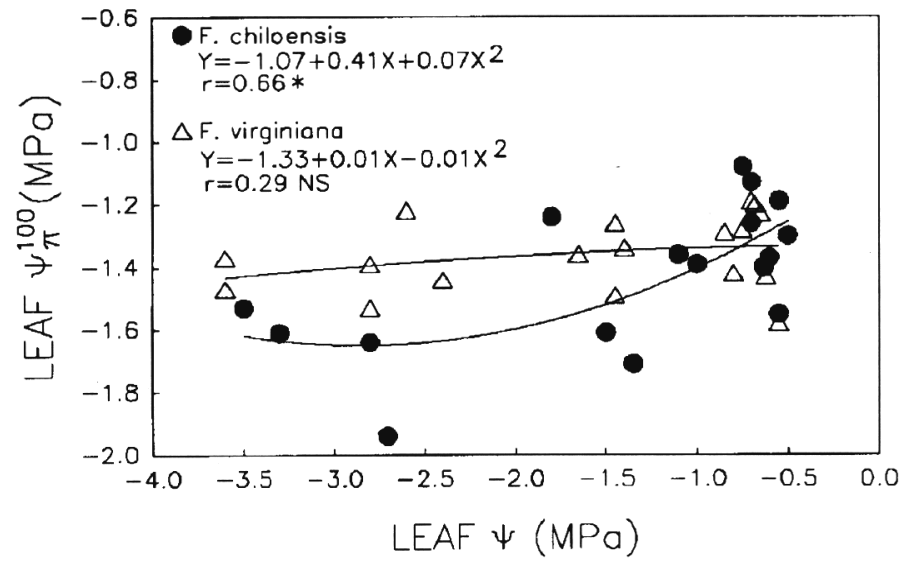

Fig. 6. Relationship between leaf $\psi_{\pi}^{100}$ and $\psi$ of $F$. chiloensis and $F$. virginiana under slowly induced water deficit stress. Two plants each of both species were grown in the same pot. Water was withheld from the plants 50 days after rooting, and measurements of leaf $\psi$ and $\psi_{\pi}^{100}$ started 23 days after withholding water began. An asterisk $(*)$ indicates that the correlation between leaf $\psi$ and $\psi^{100} \mathrm{i}$ s significant at $P \leq 00.5 \%, t$ test. Each data point represents the mean value for both plants of a species in a pot and six replicate pots.

et al., 1985). Since the stressed plants exhibited lower leaf $\psi$ regardless of the sampling time, and control and stress plants exhibited similar patterns of change, a diurnal $\psi_{\pi}$ adjustment of 0.5 $\mathrm{MPa}$ in the FC selection and $0.2 \mathrm{MPa}$ in FV selection was observed.

The water relations data in this study provided evidence for greater foliar osmotic adjustment in the FC selection 'BSP14' than in the FV selection ' $\mathrm{NCC} 85-13 \mathrm{~V}$ ' in response to water deficit stress. The lower predawn leaf $\psi_{\pi}$ in stressed than in control plants $36 \mathrm{~h}$ after re-watering following wilting (Fig. $4 \mathrm{C}$ and D), and the reduction of leaf $\psi_{\pi}{ }^{100}$ by rapidly or slowly induced stress (Fig. 1 $\mathrm{E}$ and F; Fig. .5), demonstrated greater osmotic adjustment in FC. The isothermal relationships of $\psi_{\pi}$ with leaf RWC and $\psi$, useful in determining leaf water relations components as stress progressively increases, showed that at a given leaf RWC or $\psi, \psi_{\pi}$, and $\psi_{\pi}{ }^{1}{ }^{0}{ }^{0}$ were lower in stressed than in control plants, and the difference in $\psi_{\pi}$ was much greater in FC than in FV (Fig. $2 \mathrm{C}$ and D; Fig. $3 \mathrm{C}$ and D; Fig. 6). The maintenance of turgor in stressed FC plants resulted, at least in part, from this net lowering of leaf $\psi_{\pi}$, i.e., osmotic adjustment, similar to that reported for many species (Hsiao, 1973; Jones and Turner, 1980; Morgan, 1984; Turner and Jones, 1980). These results confirmed conclusions from previous studies reporting osmotic adjustment of cultivated and wild strawberry based on a decline of leaf $\psi_{\pi}$ (O'Neill, 1983; Renquist et al., 1982c). The greater degree of osmotic adjustment that occurred in FC in response to water deficits may be a primary mechanism by which FC was characterized as more drought-resistant than FV (Darrow and Dewey, 1934).

The magnitude of osmotic adjustment is often measured as the change in osmotic potential at full turgor (Turner and Jones, 1980). Under rapidly induced water stress, the FC selection showed osmotic adjustment of $0.42 \mathrm{MPa}$, but the FV selection did not adjust (Fig. $1 \mathrm{E}$ and F). When water deficits were slowly imposed on both species at the same rate, both species exhibited osmotic adjustment, but the magnitude was $\approx 0.35 \mathrm{MPa}$ greater in $\mathrm{FC}$ than in FV (Fig. 5B). The maximum osmotic adjustment in FV leaves was $0.19 \mathrm{MPa}$, as observed in the diurnal phase (Fig. $1 \mathrm{D}$ ). Repeated stresses on FV resulted in no greater osmotic adjustment (Archbold and Zhang, 1991; Zhang and Archbold, 1992). The adjustment in FC leaves ranged from 0.20 to $0.42 \mathrm{MPa}$ (Fig. 1E; Fig. 5B), similar to other species (Bitman and Simpson, 1989; Johnson et al., 1984;
Morgan, 1984; Turner et al., 1987). The degree of osmotic adjustment, measured by thermocouple psychrometry in this study, was likely underestimated because dilution of symplastic solution with apoplastic water occurred during the freeze-thaw process (Jones and Turner, 1978; Turner, 1988). Thus, both selections could have had a somewhat greater osmotic adjustment than reported.

The magnitude of leaf osmotic adjustment in the FV selection used by O'Neill(1983) was $0.5 \mathrm{MPa}$ or greater, much greater than reported here. This difference is substantial but may be due to several causes. In the prior report (O'Neill, 1983), the plants had been grown in the field and transplanted into containers in the greenhouse before the treatments started, whereas in our study, the plants were maintained in the greenhouse continuously. Renquist et al. (1982c) reported that field-grown 'Olympus' strawberry demonstrated osmotic adjustment in the field, but not when container-grown in a growth chamber. Another cause for the disparity may be that the selection used in our study responded differently from that used by O'Neill(1983). The selection used in the prior study may have been very drought resistant. Variation in the degree of osmotic adjustment among cultivars or selections within a species has been observed with Fragaria species (Archbold, unpublished data) as well as with other species (During, 1985; Morgan, 1977; Morgan, 1983; Turner et al., 1987; Wright et al., 1983). Experimental conditions may also influence the degree of osmotic adjustment. In our studies, the magnitude of osmotic adjustment in different experiments varied for both selections because the experiments were conducted under varying light and temperature conditions. Preliminary attempts at pressure-volume analyses, the technique used by O'Neill, caused unreliable estimates of $\psi_{\pi}{ }^{100}$ due to crushing of the petiole. Similar problems have also been encountered with lupins (Lupinus spp. L.) (Turner, 1988; Turner et al., 1987). O'Neill's (1983) results, obtained using pressure-volume curves, therefore, may have been similarly affected, since petiole examination was not reported. The methodology used to estimate $\psi_{\pi} 100$ in the two studies, pressure-volume analysis vs. psychrometry following rehydration, may also contribute to the contrasting results. The degree of osmotic adjustment reported by O'Neill, up to $0.9 \mathrm{MPa}$, appears excessive in view of the values reported for other species (Turner and Jones, 1980).

During a rapidly induced drought stress, plants of FV wilted at a leaf $\psi 1.10 \mathrm{MPa}$ and $\psi_{\mathrm{P}} 0.7 \mathrm{MPa}$ higher than did those of FC (Fig. $1 \mathrm{~A}$ and $\mathrm{B})$. This difference indicated that the FC selection tolerated a lower leaf $\psi$, i.e., greater water stress, than the FV selection before wilting. The lower leaf $\psi$ at incipient wilting likely resulted from the higher degree of leaf osmotic adjustment in the FC selection than the FV selection. Determining the leaf $\psi$ and $\psi_{\pi}$ at which photosynthesis is affected in stressed plants of selections of the two species may be valuable information. Before incipient wilting, photosynthesis was impaired in $F$. ×ananassa plants as water deficit stress increased (Sruamsiri and Lenz, 1986). Another characteristic indicating the superior drought resistance of the FC selection was the leaf RWC at zero turgor from the isothermal relationships (Fig. $2 \mathrm{E}$ and F). Plants of FV started to wilt at a mean leaf RWC 13\% higher than those of FC, suggesting that FC could tolerate more cellular water loss than the FV plants (Fig. $2 \mathrm{E}$ and F). These RWC values do not take into account possible differences in water partitioning between symplastic and apoplastic compartments.

The rate of stress induction differed in the experiments when the plants were grown in separate containers, and was more rapid for FV than for FC. This difference may affect the ability of plants to osmotically adjust (Jones and Rawson, 1979; Morgan, 1984). However, when the FC and FV selections were grown and stressed 
in the same pot, the FV plants wilted $\approx 4$ days earlier than the FC plants. This difference indicated that FV lost turgor earlier than FC, even though they were exposed to the same soil water status. Thus, the rate of stress imposition had no effect on the ability of FV to respond. The inability to adequately osmotically adjust hindered FV from remaining turgid as long as FC. Evidence for net solute accumulation in stressed plants of these two species has been obtained (Zhang and Archbold, 1992). Kim and Lee-Stadelmann (1984) stated that the plant cell has two major mechanisms for avoiding water stress damage: 1) osmotic adjustment, and 2) a high cell wall elasticity. Both mechanisms will eventually have the same effect, i.e., avoidance of mechanical stress on the protoplasm layer and, especially, the cell membrane. The FC selection used in this study, which was more drought resistant than FV, exhibited at least one of these mechanisms, superior osmotic adjustment, while the FV selection had a negligible ability to respond in kind. The work of Darrow and Dewey (1934) reporting species differences in drought stress resistance may have been derived from comparison of selections similar to those in this study. Since these and other native Fragaria selections are being used in breeding and cultivar development programs, identifying and characterizing selections with superior drought resistance traits may provide a basis to develop drought resistant cultivars.

\section{Literature Cited}

Archbold, D.D. and B. Zhang. 1991. Drought stress resistance in Fragaria species, p. 138-144. In: A.. Dale and J.J. Luby(eds.). The Strawberry into the 21st Century. Timber Press, Portland, Ore.

Barlow, E.W.R. 1986. Water relations of expanding leaves, p. 45-58. In: N.C. Turner and J.B. Passioura (eds.). Plant growth, drought and dalinity. CSIRO. Melbourne, Australia.

Bitman, S. and G.M. Simpson. 1989. Drought effects on water relations of three cultivated grasses. Crop Sci. 29:992-999.

Chandler, C.K. and D.C. Ferree. 1990. Response of 'Raritan' and 'Surecrop' strawberry plants to drought stress. Fruit Var. J. 44:183-185

Darrow, G.M. 1966. The Strawberry: History, breeding, and physiology. Holt, Rinehart, and Winston, New York.

Darrow, G.M. and G.W. Dewey. 1934. Studies on the stomata of strawberry varieties and species. Proc. Amer. Soc. Hort. Sci. 32:440-447.

During, H. 1985. Osmotic adjustment in grapevines. Acta Hort. 171:315322.

Dwyer, L.M., D.W. Stewart, L. Houwing, and D. Balchin. 1987. Response of strawberries to irrigation scheduling. HortScience 22:42-44.

Elston, J., A.J. Karamanos, A.H. Kassam, and R.M. Wadworth. 1976. The water relations of the field bean crop. Phil. Trans. Royal Soc. London Ser. B. 273:581-591.

Farquhar, G.D. and T.D. Sharkey. 1982. Stomatal conductance and photosynthesis. Annu. Rev. Plant Physiol. 33:317-345.

Gehrmann, A. 1985. Growth, yield, and fruit quality of strawberries as affected by water supply. Acta Hort. 171:463-469.

Hsiao, T.C. 1973. Plant responses to water stress. Annu. Rev. Plant Physiol. 24:519-570.

Hsiao, T.C., F. Acevedo, E. Fereres, and D.W. Henderson. 1976. Stress metabolism, water stress, growth, and osmotic adjustment. Phil. Trans. Royal Soc. London Ser. B. 273:479-500.

Johnson, R.C., H.T. Nguyen, and L.I. Croy. 1984. Osmotic adjustment and solute accumulation in two wheat genotypes differing in drought resistance. Crop Sci. 24:957-962.

Jones, H.G., A.N. Lakso, and J.P. Syvertsen. 1985. Physiological control of water status in temperate and subtropical fruit trees. Hort. Rev. 7:301344.

Jones, M.M. and H.M. Rawson. 1979. Influence of rate of development of leaf water deficits upon photosynthesis, leaf $\mathrm{g}$, water use efficiency, and osmotic potential in sorghum. Physiol. Plant. 45: 103-111.

Jones, M.M. and N.C. Turner. 1978. Osmotic adjustment in leaves of sorghum in response to water deficits. Plant Physiol. 61:122-126.

Kim, J.H. and O.Y. Lee-Stadelmann. 1984. Water relations and cell elasticity quantities in Phaseolus vulgaris leaves. J. Expt. Bot. 35:841858.

Kramer, P.J. 1983. Water deficits and plant growth, p. 342-415. In: P.J. Kramer (ed.). Water Relations of Plants. Academic Press, New York.

Ludlow, M.M. and R.C. Muchow. 1990. A critical evaluation of traits for improving crop yields in water-limited environments. Adv. Agron. 43:107-153.

Mazhorov, E.V. 1978. Comparative drought resistance of strawberry from different ecologico-geographical zones. Vses. Ordena Linina Inst. Rastenievodstva imeni N.I. Vavrilova. 86:18-21. (Hort. Abstr. 1980. $50: 425)$

Morgan, J.M. 1977. Differences in osmoregulation between wheat genotypes. Nature 270:235.

Morgan, J.M. 1983. Osmoregulation as a selection criterion for drought tolerance in wheat. Aust. J. Agr. Res. 34:637-651.

Morgan, J.M. 1984. Osmoregulation and water stress in higher plants. Annu. Rev. Plant Physiol. 35:299-319.

O'Neill, S.D. 1983. Role of osmotic potential gradients during water stress and leaf senescence in Fragaria virginiana. Plant Physiol. 72:931937.

Renquist, A.R., P.J. Breen, and L.W. Martin. 1982a. Vegetative growth response of 'Olympus' strawberry to polyethylene mulch and drip irrigation regimes. J. Amer. Soc. Hort. Sci. 107:369-372.

Renquist, A.R., P.J. Breen, and L.W. Martin. 1982b. Effect of polyethylene mulch and summer irrigation regimes on subsequent flowering and fruiting of 'Olympus' strawberry. J. Amer. Soc. Hort. Sci. 107:373-376. Renquist, A.R., P.J. Breen, and L.W. Martin. 1982c. Influence of water status and temperature on leaf elongation in strawberry. Scientia. Hort. 18:77-85

Sruamsiri, P. and F. Lenz. 1986. Photosynthesis and stomatal behaviour of strawberries. IV. Effects of water deficiency. Gartenbau. 51:84-92. Turner, N.C. 1986. Crop waterdeficits: A decade of progress. Adv. Agron. 39:1-51.

Turner, N.C. 1988. Measurement of plant water status by the pressure chamber technique. Irr. Sci. 9:289-308.

Turner, NC. and M.M. Jones. 1980. Turgor maintenance by osmotic adjustment: A review and evaluation, p. 155-172. In: N.C. Turner and P.J. Kramer (eds.). Adaptation of plants to water and higher temperature stress. Wiley-Interscience, New York.

Turner, N.C., W.R. Stem, and P. Evans. 1987. Waterrelations andosmotic adjustment of leaves and roots of lupins in response to water deficits. Crop Sci. 27:977-983.

Wright, S.T.C., R.C.G. Smith, and J.M. Morgan. 1983. Differences between the grain sorghum genotypes in adaptation to drought stress. III. Physiological responses. Aust. J. Agr. Res. 34:637-651.

Zhang, B. and D.D. Archbold. 1992. Solute accumulation in leaves of Fragaria chiloensis and $F$. virginiana responds to water deficit stress. J. Amer. Soc. Hort. Sci. 118:280-285. 